\title{
O desenvolvimento psicológico do adulto com deficiência adquirida: contribuições de A. R. Luria na obra O homem com um mundo estilhaçado
}

\author{
Eliza Maura Castilho Lopes, Lucia Pereira Leite, \\ Carmen Maria Bueno Neme, Tânia Gracy Martins Valle \\ Universidade Estadual Paulista Júlio de Mesquita Filho, Bauru, SP, Brasil
}

Resumo

Adquirir uma deficiência pode implicar em importantes transformações na vida de um adulto. Segundo pressupostos da Teoria Histórico-Cultural, o desenvolvimento do indivíduo continuará ocorrendo, considerando suas condições objetivas. Para explorar como ocorre esse desenvolvimento e qual o papel da Psicologia enquanto ciência diante do sujeito que adquire uma deficiência, será analisado o livro "O homem com um mundo estilhaçado", de A. R. Luria, que conta a história de um indivíduo adulto que sofre uma lesão cerebral. A obra será discutida com base em pressupostos teóricos do próprio Luria, e de teóricos da mesma abordagem, como Vigotski e Leontiev.

Palavras-chave: deficiência; deficiência adquirida; desenvolvimento do adulto.

\section{The psychological development of adults with acquired disabilities: contributions from A. R. Luria's work The man with a shattered world}

\begin{abstract}
Acquiring a disability can result in major changes in an adult's life. According to the Cultural-Historic Psychology, the individual development will continue to occur, taking into account his objective conditions. To explore how this development occurs and the role of Psychology towards the subjects who acquire a disability, this paper aims to analyze the book "The man with a shattered world," of A. R. Luria, that tells the story of an adult who suffered a brain injury. The book will be discussed based on Luria's theoretical premisses, and on others authors of the same theoretical approach, like Vigotski and Leontiev.
\end{abstract}

Keywords: disability; acquired disability; adult development.

\section{Introdução}

No desenvolvimento de seus estudos, Alexander Romanovich Luria contribuiu sobremaneira para o desenvolvimento da Neuropsicologia, trazendo um conhecimento consistente a respeito da base cerebral envolvida nos fenômenos psicológicos. Segundo o autor, a área pode ser definida como "um ramo novo da ciência cujo objetivo específico e peculiar é a investigação do papel de sistemas cerebrais individuais em formas complexas de atividade mental" (LURIA, 1981, p. 4). Com base em conceitos originados dos estudos de Lev Seminovich Vigotski, ${ }^{1}$ e trabalhando em conjunto com este autor, Luria desenvolveu pesquisas que ampliaram a concepção a respeito do funcionamento e da estrutura que permite a existência das funções psicológicas superiores.

Akhutina (2002) explicita que Vigotski já havia construído uma base importante para a compreensão do cérebro e da consciência, ao ressaltar o papel fundamental da interação social e da experiência histórica na formação do psiquismo. Para o autor, a interação social interiorizada é o que funda a consciência, tornando a experiência duplicada - na existência material e enquanto reflexo na consciência (VIGOSTKI, 1991). Luria (2001) também discorre a respeito, e em sua obra Pensamento e Linguagem... (LURIA, 2001) ressalta a importância da linguagem nesse

\footnotetext{
^Endereço para correspondência: Universidade Estadual Paulista Júlio de Mesquita Filho, Faculdade de Ciências de Bauru, Departamento de Psicologia. Av. Eng. Luiz Edmundo Carrijo Coube - Vargem Limpa. CEP: 17033360 - Bauru, SP - Brasil.E-mail: eliza.mclopes@gmail.com, lucialeite@fc.unesp.br, cmneme@gmail.com,tgvalle@uol.com.br

${ }^{1}$ De origem russa, o nome do autor é grafado em alfabeto cirílico e sua escrita em alfabeto romano possui variações de acordo com as publicações e traduções de sua obra. Nesse texto a grafia adotada é Vigotski, salvo em citações literais.
}

processo. Além de sua função comunicativa, a linguagem é fundamental no desenvolvimento da cognição, da percepção e da memória, agindo como um fator de organização da "vida interior". Para Luria, a linguagem é uma das principais responsáveis pela gênese do ato voluntário consciente do homem.

A aquisição da linguagem envolve a apropriação de um conteúdo socialmente construído por meio do significado. Ao discorrer a respeito, o teórico faz referência aos apontamentos de Vigotski (2008) na obra Pensamento e Linguagem, publicada originalmente no ano de 1934, que discute os significados e os sentidos. Para Luria, o significado consiste no sistema de relações formado objetivamente no processo histórico que se encontra na palavra. Nas palavras do autor, "assimilando o significado das palavras, dominamos a experiência social" (LURIA, 2001, p. 45). Já o sentido refere-se ao significado individual da palavra, ou seja, algo que difere de pessoa para pessoa, e está ligado às suas próprias vivências afetivas e sociais.

Considerando o caráter social e histórico do desenvolvimento do que Vigotski convencionou chamar de sistema psicológico, o autor desenvolveu aqueles que, complementados pelos estudos de Luria, seriam os três princípios básicos da Neuropsicologia contemporânea a respeito das funções psicológicas superiores: sua organização sistêmica, sua gênese social e sua localização dinâmica. 
A organização sistêmica das funções diz respeito a uma nova compreensão do cérebro e de seu funcionamento. Nas palavras de Luria (1981, p. 16), "as funções mentais, como sistemas funcionais complexos, não podem ser localizadas em zonas estreitas do córtex ou em agrupamentos celulares isolados, mas devem ser organizadas em sistemas de zonas funcionando em concerto".

Essa perspectiva permitiu avanços importantes na Neuropsicologia em relação ao diagnóstico de síndromes e efeitos de lesões adquiridas, considerando a complexidade do sistema psicológico. Garantiu-se também avanços nas possíveis intervenções apresentadas em processos de reabilitação.

O princípio da gênese social é o que indica que as funções psicológicas surgem inicialmente em uma relação interpsicológica - nas relações sociais, para então se tornarem intrapsicológicas. Com relação a isso, Vigotski (1991) explica que o sistema se forma em três etapas: na primeira uma pessoa manda, e a outra executa; na segunda etapa a pessoa fala consigo mesma, seguindo o mesmo processo inicial; já em um terceiro momento, de maneira intrapsicológica, dois pontos cerebrais se unem em um sistema, formando um ponto intracortical. Nesse sistema, o aprendizado que parte das interações leva ao desenvolvimento.

O princípio da localização dinâmica das funções superiores, unido aos dois princípios anteriores, indica a variabilidade dos sistemas funcionais, como indicado por Akhutina e Pylaeva (2011). As autoras apontam que essa variabilidade está relacionada a três fatores: a modificação da estrutura funcional pela ontogênese, a modificação dos sistemas pelos níveis de automatização das funções e a possibilidade de uso de diferentes meios para alcançar os mesmos resultados. Com isso a localização dos sistemas ligados às funções psicológicas superiores será alterada de acordo com o desenvolvimento do indivíduo e suas condições histórico-sociais.

Grande parte das pesquisas de Luria envolveu a investigação clínica de pacientes com deficiência principalmente em função de lesões cerebrais, tanto inatas como adquiridas em decorrência de traumas. Como pontuam Toni, Romanelli e Salvo (2005) a pesquisa envolvendo aspectos patológicos é uma prática comum na Neuropsicologia, uma vez que, pelo estudo da disfunção é possível compreender a função cerebral.

Ao mesmo tempo, estudos envolvendo pessoas com deficiência puderam dar nova perspectiva em relação ao desenvolvimento das mesmas. Vigotski (1997, originalmente publicado em 1934) traz no quinto volume da coleção Obras Escogidas - Fundamentos da Defectologia - que a tipologia da deficiência é abordada à luz de duas perspectivas, a primária e a secundária. A deficiência primária, para o autor, se ancora numa concepção organicista, e abarca uma série de comprometimentos no organismo decorrentes de padrões genéticos diferenciados, lesões neurais, malformações hereditárias, formações anômalas e outras ocorrências que levem a um funcionamento diferenciado do organismo físico.

Já a deficiência secundária decorre dos prejuízos ocasionados pela dificuldade no estabelecimento das interações sociais e, consequentemente, da inadequação da apropriação de conhecimentos necessários para o pleno desenvolvimento humano. Tal concepção é subsidiada na premissa da construção histórica do biológico, em função do social. A adoção dessa perspectiva não procura negar a existência de mudanças orgânicas em função das deficiências, mas sim compreendê-la como um fenômeno social. Com sua significação histórica e cultural, a deficiência deixa de ser exclusivamente um fato natural.

Considerando os princípios expostos, a Psicologia Histórico-Cultural permite ampliar a compreensão do fenômeno da deficiência, estendendo a sua amplitude para o contexto de sua ocorrência. Ou seja, remove-se o foco de atenção do sujeito que a apresenta, e passa-se a compreendê-la enquanto atributo dado pela sociedade diante de diferenças físicas, anatômicas sensoriais, cognitivas e/ou comportamentais.

Um dos estudos realizados no atendimento a pessoas com deficiência foi relatado por Luria (2008[1971]) no livro $O$ homem com um mundo estilhaçado, publicado em 1971 em Moscou. A obra configurou um estudo de caso pormenorizado de um indivíduo em condição de deficiência adquirida, atendido pelo autor, compondo o que Luria chamou de romance acadêmico. No livro um caso foi discutido de maneira científica, porém fazendo uma alusão ao indivíduo como um todo, com suas vivências afetivas, sua história e suas próprias impressões a respeito de seu estado. O estilo, admirado e reproduzido por neurologistas como o inglês Oliver Sacks em obras como $O$ homem que confundiu sua mulher com um chapéu (1985), e Um antropólogo em marte (1995), favorece a compreensão do leitor a respeito de considerações teóricas, por meio de exemplos concretos e claros, além de possibilitar o acesso a um método de estudo pautado na perspectiva da Psicologia Histórico-Cultural. Por essa razão optou-se por fazer da obra $O$ homem com um mundo estilhaçado (LURIA, 2008[1971]) objeto central de análise nesse artigo, com o objetivo de expor as contribuições de Luria em relação à deficiência adquirida e suas implicações para o desenvolvimento do indivíduo.

\section{"História de um terrível ferimento no cérebro"}

$\mathrm{Na}$ obra analisada, Luria conta a história verídica de Zasetsky, um subtenente que no ano de 1943, aos vinte e três anos, tem seu cérebro lesionado por um estilhaço de projétil que $\mathrm{o}$ atingiu durante um confronto militar. $\mathrm{O}$ ferimento, embora localizado em uma área pequena, alcançou um nível importante de gravidade, alterando os tecidos próximos a ele e causando uma atrofia parcial da medula.

No decurso de vinte e cinco anos, Luria acompanhou o paciente e pode observar os efeitos que o acidente causou na vida de Zasetsky. Baseado em fragmentos do diário escrito pelo próprio paciente, Luria intercala o relato da 
biografia com explanações a respeito do funcionamento do cérebro humano e das funções psicológicas. Segundo o autor, Zasetsky sofrera uma lesão no córtex visual terciário, que, por sua vez, é responsável por "combinar as seções visual (occipital), táctil-motora (parietal) e auditiva-vestibular (temporal do cérebro)" (LURIA, 2008[1971], p.48). Na ocorrência de um ferimento em tal região a capacidade visual do sujeito pode permanecer inalterada, no entanto, surgimentos de pontos de cegueira são comuns, ou a perda de até metade do campo visual. Nessa condição também é possível que o indivíduo perca sua capacidade de combinar as sensações num todo coerente, passando a perceber e decodificar o mundo de modo fragmentado. Alguns dos sintomas observados no cotidiano de Zasetsky exemplificam tal descrição. Em um dos trechos de seu diário, o mesmo afirma: "Continuo não vendo de maneira completa objetos [...]. Quando olho uma colher, pela extremidade esquerda, fico pasmo. Não consigo imaginar por que só vejo a extremidade da colher e não a colher inteira" (LURIA, 2008[1971], p. 54).

Outro aspecto que ficou comprometido em decorrência da lesão sofrida foi a linguagem. Em trechos de seu diário, Zasetsky descreve situações em que, embora se lembrasse do objeto, não se recordava da sua nomenclatura, tendo dificuldades na nomeação e, consequentemente, no compartilhamento de informações. Por diversas vezes ocorria-lhe o contrário, quando lhe falavam o nome de um objeto e ele não conseguia identificar o que seria aquilo, ou seja, tinha dificuldades em elaborar a representação mental do mesmo. Igualmente era difícil para ele executar algumas ações cotidianas de fácil realização em momentos anteriores ao do acidente. Relata, por exemplo, ter sido solicitado por sua irmã para que arrumasse a porta do celeiro do local onde moravam. Embora as ferramentas estivessem à sua disposição, ele não sabia mais como manuseá-las, ou mesmo quais seriam as suas utilizações.

De maneira geral, o quadro apresentado por Zasetsky era grave, e sua vida de forma geral havia sofrido mudanças expressivas. Em relação a si mesmo, se afirmava enquanto uma pessoa anormal, [...] "sem qualquer serventia, incapaz para qualquer tipo de trabalho, para absolutamente nada" (LURIA, 2008[1971], p. 33).

Com o passar do tempo, Zasetsky percebeu que as habilidades de leitura e escrita haviam sofrido alterações radicais. Palavras em russo, idioma de domínio linguístico, the pareciam escritas em outra língua, e era difícil decifrá-las. Na escrita não era diferente, embora tenha descoberto durante o período de tratamento, por intermédio da equipe médica, que ao escrever automaticamente e sem pensar, era capaz de redigir palavras com sucesso e coerência textual. Luria explica a ocorrência desse fenômeno relatando que nos adultos a escrita já é uma habilidade automática, envolvendo uma série de movimentos já incorporados durante a aprendizagem. Como suas habilidades cinético-motoras estavam preservadas e já eram automáticas, era possível que ele escrevesse com facilidade.
Apesar das dificuldades que a lesão cerebral lhe acarretara, Zasetsky se predispôs a aprender novamente a ler e a escrever, recorrendo às aulas com uma professora. $\mathrm{O}$ aprendizado fazia perceber o quão distante, em termos de aprendizado acadêmico, ele se encontrava do estado em que estava antes do acidente. No entanto, este fato lhe impulsionava a buscar aprender aquilo de que havia se esquecido (ou perdido) e Zasetsky mostrava-se um aluno comprometido.

Durante sua experiência acadêmica, o ex-tenente começou a desenvolver estratégias que lhe permitiam aprimorar seus resultados, criando um sistema próprio para memorizar as letras que lhe fugiam durante a leitura. Segundo ele, citado por Luria em trechos do livro, uma das estratégias consistia em utilizar palavras como lembretes. Por exemplo, para lembrar-se da letra k, recordava-se da palavra krov, que em russo significa sangue. Esta palavra vinha-lhe constantemente à lembrança, e assim, ele não se esquecia da letra e sua morfologia.

Luria conta que, após a evolução na escrita, Zasetsky resolveu redigir um diário em que discursava sobre sua história. Essa atividade exigia horas de empenho do autor, pelas dificuldades na escrita e na leitura do que havia escrito. Mesmo assim, ele prosseguiu dedicando-se a esta atividade, passando vinte e cinco anos redigindo seu diário que, ao final deste período, contabilizou um montante próximo a três mil páginas.

Zasetsky afirmava ser incapaz de desempenhar outras atividades, uma vez que se via impossibilitado de ajudar em sua casa, ou de sair pela rua a passeio, pois com frequência se perdia. Por essa razão relata ter dedicadose a escrever. Luria (2008[1971], p. 87) afirma que, na escrita, Zasetesky buscava relatar a própria história, descrevendo suas deficiências, dificuldades e a trajetória de sua vida, $[\ldots]$ "para formular e tornar coerentes os problemas enfrentados por um homem quando seu mundo se desintegra subitamente".

Luria afirma no livro que a motivação que seu paciente tinha para a escrita de suas memórias vinha de diversos âmbitos. Por um lado, contar sua história lhe dava uma razão para viver, pois, por meio da escrita, seu pensamento se dava de maneira mais ágil, e aos poucos, sua memória se ampliava. Por outro lado, Zasetsky tinha a esperança de que por meio de seu relato os médicos pudessem compreender melhor a doença que tinha, e até mesmo descobrir sua cura.

Luria conta, ao final da obra, que a história de Zasetsky era uma história inacabada, pois na época em que deixou de atende-lo o mesmo continuava vivendo com sua família, e prosseguia com sua atividade diária de escrever sua história. Sua memória, embora tenha progredido durante esse processo, ainda se encontrava severamente comprometida. No entanto, o ex-paciente prosseguiu com sua determinação em aprender os conteúdos acadêmicos, abrangendo áreas mais complexas como questões matemáticas e outros conceitos que envolviam o pensamento abstrato em 
sua forma mais elevada. Embora os progressos fossem poucos, Zasetsky persistiu no propósito de (re)aprender e no contínuo desenvolvimento.

\section{Contribuições da obra para a compreensão do} desenvolvimento da pessoa com deficiência adquirida

São diversas as contribuições da obra $O$ homem com um mundo estilhaçado (LURIA, 2008[1971]) para o estudo da Neuropsicologia e da deficiência. Mais do que isso, em seu romance acadêmico, com fortes traços biográficos, Luria apresenta um método de pesquisa a ser reproduzido: o estudo de caso com bases na Psicologia Histórico-Cultural. Considerando questões biológicas, culturais e históricas relacionadas ao caso, o autor apresenta uma visão abrangente de Zasetsky. Superando a mera descrição de um caso clínico, Luria envolve as dimensões sociais e culturais que envolvem seu paciente.

Para tanto, Luria faz uso de um importante recurso: as próprias memórias de Zasetsky na forma de diário. Esse meio foi fundamental para o estudo, pois, nas palavras do autor,

Descrevendo seu infortúnio, ele nos legou não apenas um documento trágico, mas também algumas informações inestimáveis. De fato, quem será mais capaz de descrever um evento do que alguém que tenha sido, ele próprio, sua testemunha ocular, participante e vítima. Tendo sido vítima dessa doença, ele se empenhou em investigá-la. A descrição que faz é excepcionalmente clara e detalhada; se o acompanharmos passo a passo, poderemos desvendar alguns dos mistérios do cérebro humano (LURIA, 2008[1971], p. 93).

Com essa descrição, Zasetsky ocupa um papel central em seu próprio tratamento, e ao mesmo tempo possibilita a Luria uma compreensão ampla a seu respeito.

Outro aspecto de destaque nas memórias de Zasetsky, apresentado por Luria, é o relato de sua história de vida. Oliveira, Rego e Aquino (2006), ao discorrer a respeito das narrativas autobiográficas, apontam que estas podem funcionar como um fator de organização da história vivida pelo próprio autor, dando forma ao discurso sustentado pela própria vida. Nas palavras dos autores,

Trata-se enfim de compreender as narrativas autobiográficas como uma espécie de dispositivo sociocultural de repatriamento de experiências subjetivas fragmentárias, provisórias e dispersivas, já que estas parecem representar sua condição de possibilidade no mundo contemporâneo (OLIVEIRA; REGO; AQUINO, 2006, p. 135).

De maneira geral, com o estudo do caso de Zasetsky, o autor traz à tona conceitos teóricos, como os fundamentos da Neuropsicologia mencionados anteriormente, que possibilitam a compreensão das funções psicológicas diante da lesão cerebral. Analisando os sintomas do ex-tenente, é possível compreender como a lesão em determinado centro pode afetar algumas habilidades, implicando no fato de que a região - enquanto sistema - era a responsável pelas áreas em questão. Simultaneamente, considerando que habilidades automáticas, como a escrita 'sem pensar' mencionada por Luria, continuavam preservadas, é possível exemplificar os efeitos do desenvolvimento nas funções cerebrais. Segundo o autor, o desenvolvimento dos processos psicológicos permite a mudança da estrutura cerebral e resulta no uso de novos sistemas em diferentes zonas corticais (LURIA; SIMERNITSKAYA; TUBYLEVICH, 1970). Assim, habilidades como a escrita mencionadas na história de Zasetsky envolvem sistemas distintos dependendo do nível de desenvolvimento dessa função.

A ocorrência de mudanças nos sistemas que estruturam as funções psicológicas superiores reafirma o princípio da gênese social das mesmas. Como pontuado por Akhutina (2002, p. 118), "si inicialmente las funciones se determinan por mecanismos biológicos, más tarde éstas los determinan a ellos". As mudanças na estrutura e na localização dinâmica das funções superiores também garantem a possibilidade de reorganização das mesmas, ainda que com limitações. Toni, Romanelli e Salvo (2005) afirmam que a mobilidade das estruturas do sistema funcional tem como consequência a plasticidade. Desse modo, se há comprometimento de áreas específicas do sistema, outras áreas possibilitam a reestruturação da função envolvida, ainda que com modificações nos mecanismos envolvidos. Com isso, a reabilitação cognitiva torna-se uma possibilidade viável, garantindo o reestabelecimento de funções cognitivas.

Se em termos neuropsicológicos a reabilitação é viável, as interações sociais, tão relevantes para o desenvolvimento das funções psicológicas, são influenciadas por concepções diversas a respeito da deficiência. Conforme o conceito de deficiência primária e secundária, é possível considerar que as interações sociais no meio em que o indivíduo se encontra definirão não apenas os significados de sua deficiência, mas também as condições para o desenvolvimento daquele com tal atributo.

Em consonância com tal proposta, Teixeira e Guimarães (2006, p. 192), afirmam que a "a incapacidade existe em função da relação das pessoas portadoras de deficiência e o seu meio ambiente, o que gera a desigualdade de condições com os demais" (TEIXEIRA; GUIMARÃES, 2006, p. 192). O mesmo é proposto por Omote (1995), que apresenta tal fenômeno enquanto uma categoria construída socialmente, uma vez que apenas na comparação entre indivíduos e à luz de uma audiência social é que as diferenças são classificadas e consideradas negativas ou positivas.

Considerando a noção de deficiência exposta, observase que ao indivíduo que se encontra nessa condição, poderão ser atribuídas diferentes características, categorizando-o em um grupo heterogêneo, num processo de estigmatização. A esse grupo pode ser atribuída uma conotação negativa, num processo de desvalorização dos indivíduos que pertencem a ele. $\mathrm{O}$ diário do próprio Zasetsky mostra essa desvalorização: quando as transformações sofridas afetam sua capacidade de desempenhar funções antes tão fáceis, ele relata a impressão de incapacidade e pouco mérito.

Fractal, Rev. Psicol., v. 28 - n. 1, p. 63-68, 2016 
Apesar disso, o relato de Luria sobre Zasetsky demonstra a singularidade do desenvolvimento humano após a aquisição de uma deficiência. Apesar da lesão cerebral ter alterado sobremaneira o sistema psicológico de Zasetsky, as intervenções e as estratégias de ensino utilizadas possibilitaram ao paciente o desenvolvimento do aprendizado.

Andrade e Smolka (2012), abordando temáticas relacionadas à neuropsicologia sob a ótica de Luria e Vigostki, vêm relatar a importância da efetivação de um maior número de experiências que visem a partilha de produtos culturais que impulsionem o desenvolvimento das funções psicológicas superiores, em pessoas com ou sem deficiência. As autoras apontam para a apropriação como mecanismo para esse desenvolvimento, afirmando que "a internalização é algo que fazemos com tudo aquilo que ouvimos e a que prestamos atenção, mas a apropriação exige que aquilo a que se prestou atenção seja 'tornado próprio' do pensamento e da consciência de quem se apossa do conhecimento" (ANDRADE; SMOLKA, 2012, p. 708, grifo do autor).

Vigotski (2011), ao tratar da educação de crianças com deficiência, afirmou que, por si só, seguindo seu desenvolvimento natural, estas de fato encontrarão impeditivos para aprendizado dos conceitos, em decorrência dos limites sensoriais, físicos e/ou cognitivos. No entanto, com o desenvolvimento cultural, pelo intermédio de estratégias intencionais que permitam o aprendizado, é possível a obtenção de resultados que indicam apropriações de conhecimentos. $\mathrm{O}$ autor afirma que pessoas com deficiência demonstram que o desenvolvimento de comportamentos não está relacionado necessariamente a uma ou outra função orgânica. Portanto, cabe à área da educação o desenvolvimento cultural para atingir os resultados desejados. Nas palavras do teórico, [...] "onde não é possível avançar no desenvolvimento orgânico, abre-se um caminho sem limites para o desenvolvimento cultural" (VIGOTSKI, 2011, p. 869).

No mesmo sentido, Oliveira e Rego (2010) discutem a contribuição de Luria para a compreensão do desenvolvimento de pessoas com deficiência. As autoras afirmam que, diante da importância das interações, da cultura na construção de processos psíquicos e do papel do sujeito na apropriação da experiência históricocultural, o processo de desenvolvimento segue uma trajetória singular para cada pessoa. Nas palavras das autoras, Luria enfatiza o caráter de desenvolvimento singular, mesmo após situações adversas, em que

um mesmo ponto de partida nunca levará a um mesmo ponto de chegada. Portanto, é preciso ver os sujeitos portadores de algum tipo de deficiência como sujeitos completos, e estudar o modo como manejam e aplicam os recursos disponíveis, na medida em que isso pode levá-los a compensar seus déficits específicos mediante outros tipos de recursos (OLIVEIRA; REGO, 2010, p. 116).

Numa digressão sintética da obra $O$ homem com um mundo estilhaçado (LURIA, 2008[1971]), é possível aprimorar a compreensão a respeito do desenvolvimento psicológico do indivíduo que adquire uma deficiência. Embora esta condição imponha limitações que devem ser consideradas, está claro que as mesmas não podem ser entendidas erroneamente como impeditivas para a humanização e o desenvolvimento de funções superiores. Sabe-se que o caminho para a realização de tal objetivo deverá ser distinto, porém, como bem versado por Luria, entende-se que o psiquismo é fruto de uma construção social, que por si só pode levar ao desenvolvimento de processos diversos cognoscitivos, mesmo com o limitante aparato orgânico.

Todavia, para que o processo de humanização continue na sua progressão faz-se necessário o acesso às condições objetivas existentes no contexto social. Mais do que a reabilitação, é importante viabilizar meios para permanência das pessoas com deficiência nas mais diversas esferas sociais, com a adequação de estruturas que respeitem suas singularidades.

Tal qual a história de Zasetsky, o desenvolvimento das pessoas com deficiência adquirida pode ser considerado uma história inacabada, que poderá ter diferentes direcionamentos em função das condições materiais de existência disponíveis para tais indivíduos. É preciso então garantir à pessoa com deficiência formas diversas de participação social. Para isso é necessário entender que diferentes modos funcionamentos (orgânico, cognitivo, sensorial e/ou comportamental) fazem parte da natureza humana e, portanto, cabe à sociedade apresentar ações responsivas no atendimento às especificidades de todos sujeitos, com vistas a garantir formas mais plenas de desenvolvimento.

Para finalizar, é oportuno anunciar que as páginas aqui traçadas não têm a intenção de esgotar os ideários da obra referenciada, mas sim de provocar o leitor a resgatar a obra $O$ homem com um mundo estilhaçado (LURIA, 2008[1971]), numa perspectiva crítica da deficiência. Nessa perspectiva compreende-se a natureza social desse fenômeno - deslocando-o do sujeito com deficiência para o âmbito social - e as devidas implicações dessa nova visão, que permitem ao mesmo inúmeras possibilidades de desenvolvimento.

\section{Referências}

AKHUTINA, T. V. L. S. Vigotsky y A. R. Luria: la formación de la neuropsicologia. Revista Espanhola de Neuropsicologia, v. 4, n. 2-3, p. 108-129, 2002.

AKHUTINA, T. V.; PYLAEVA, N. M. L. Vygotsky, A. Luria and Development Neuropsychology. Psychology in Russia: state of art., p. 155-175, 2011.

ANDRADE, J. J.; SMOLKA, A. L. B. Reflexões sobre desenvolvimento humano e neuropsicologia na obra de Vigotski. Psicol. estud., [S.1.], v. 17, n.4, p. 699-709, 2012.

LURIA, A. R. Fundamentos de neuropsicologia. São Paulo: Edusp, 1981.

LURIA, A. R. Pensamento e linguagem: as últimas conferências de Luria. 2. ed. Porto Alegre: Artes Médicas, 2001.

LURIA, A. R. O homem com um mundo estilhaçado (1971). Petrópolis: Vozes, 2008. 
LURIA, A. R.; SIMERNITSKAYA, E. G; TUBYLEVICH, B.

The structure of psychological processes in relation to cerebral organization. Neuropsychologia, [S.1.], v. 8, p. 13-19, 1970.

OLIVEIRA, M. K.; REGO, T. C. Contribuições da perspectiva histórico-cultural de Luria para a pesquisa contemporânea. Educação e Pesquisa, São Paulo, v. 36, n. especial, p. 107-121. 2010.

OLIVEIRA, M. K.; REGO, T. C.; AQUINO, J. G. Desenvolvimento psicológico e constituição de subjetividades: ciclos de vida, narrativas autobiográficas e tensões da contemporaneidade. Pro-Posições, [S.1.], v. 17, n. 2 (50), p. 119-138, maio/ago. 2006.

OMOTE, S. A Integração do deficiente: um pseudo-problema científico. Temas em Psicologia, [S.1.], v. 3, n. 2, p. 55-62, 1995.

TEIXEIRA, A. M.; GUIMARÃES, L. Vida revirada: deficiência adquirida na fase adulta produtiva. Revista MalEstar e Subjetividade, [S.1.], v. VI, n. 1, p. 182-200, 2006.

TONI, P. M. D.; ROMANELli, E. J.; SALVO, C. G. D. A evolução da Neuropsicologia: da antiguidade aos tempos modernos. Psicologia Argumento, v. 23, n. 41 p. 47-55, 2005.

SACKS, O. O homem que confundiu sua mulher com um chapéu. Rio de Janeiro: Imago, 1985.

SACKS, O. Um antropólogo em marte. São Paulo: Companhia das Letras, 1995.

VIGOTSKI, L. S. Obras Escogidas. Madri: Visor, 1991. v. 1.

VIGOTSKI, L. S. Obras Escogidas. Madri: Visor, 1997. v. 5.

VIGOTSKI, L. S. Pensamento e linguagem. Tradução de Jefferson Luiz Camargo. 4. ed. São Paulo: Martins Fontes, 2008.

VIGOTSKI, L. S. Adefectologia e o estudo do desenvolvimento e da educação da criança anormal. Educação e Pesquisa, São Paulo, v. 37, n. 4, p. 861-870, dez. 2011.

Recebido em: 4 de julho de 2013

Aceito em: 25 de junho de 2015 